
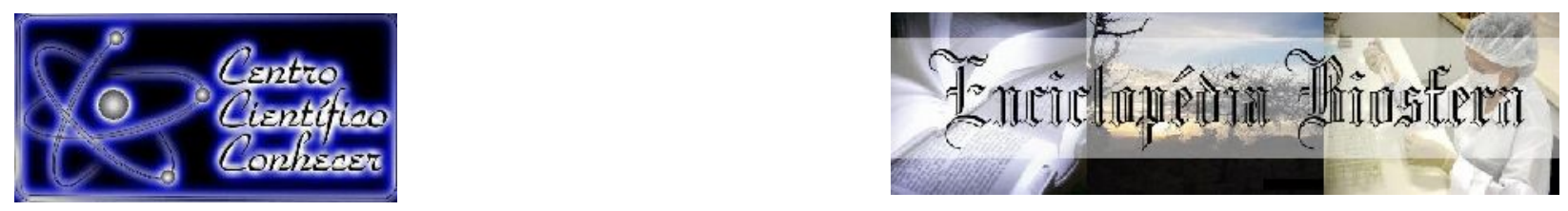

\title{
ESTUDO COMPARATIVO ENTRE O SISTEMA CONSTRUTIVO DE CONTÊINER MARÍTIMO E SISTEMA DE CONCRETO-PVC EM SÃO LUÍS - MA
}

Camilla Gomes Arraiz ${ }^{1}$, Moises de Araujo Santos Jacinto ${ }^{2}$, Marcos Henrique Costa Coelho Filho $^{3}$, Leticia Maria Brito Silva ${ }^{4}$, Paulo Nunes e Silva Albuquerque ${ }^{5}$

1 Engenheira civil. Pós-graduanda em Estruturas de concreto armado e fundações pelo Instituto Brasileiro de Educação Continuada INBEC, São Luís, Maranhão, Brasil.

2 Engenheiro civil. Mestrando em Estruturas e Construção Civil pela Universidade

Federal do Pará UFPA - Belém, Pará, Brasil.

3 Engenheiro civil. Pós-graduando em Master Bim: Ferramentas de gestão e projeto pelo Instituto de Pós-graduação e Graduação (IPOG), São Luís, Maranhão, Brasil. 4 Engenheira civil. Bacharel em Engenharia Civil pela Universidade CEUMA - São Luís, Maranhão, Brasil.

5 Engenheiro civil. Mestrando em Estruturas e Construção Civil pela Universidade Federal do Pará UFPA - Belém, Pará, Brasil.

Email de contato: moisesaraujosantosjacinto@gmail.com

\section{Recebido em: 15/08/2020 - Aprovado em: 15/09/2020 - Publicado em: 30/09/2020} DOI: 10.18677/EnciBio_2020C22

\begin{abstract}
RESUMO
Os Métodos Construtivos Industrializados vêm ganhando espaço no mercado brasileiro, a medida em que se necessita de sistemas mais eficientes e econômicos na construção civil, com diminuição dos desperdícios dos materiais e alta produtividade. Nesta pesquisa, foram abordados o Método Construtivo com Contêiner Marítimo, que utiliza o próprio contêiner para construção de edificações, e - Método Concreto-PVC, o qual utiliza perfis de PVC, encaixados entre si e preenchidos com concreto e aço, formando as paredes da edificação. Com isso, foi feito um estudo comparativo entre estes métodos e identificado aquele mais viável para construção de uma habitação na cidade de São Luís - MA. Para isso, realizouse uma pesquisa bibliográfica e foram elaborados os projetos arquitetônicos, estrutural e complementares de uma residência padrão, assim como foram feitas as planilhas orçamentárias, o dimensionamento de equipes e o planejamento de execução da obra, para cada método. Os resultados mostraram que o método com Contêiner Marítimo apresenta uma economia de $\mathrm{R} \$ 1.352,44$ no custo total e menor custo de mão de obra, com uma diferença de $R \$ 1.167,60$. Este sistema também apresentou vantagem no tempo de execução, necessitando de apenas 19 dias, enquanto o Concreto-PVC precisou de 27 dias. Sendo assim, o sistema construtivo com Contêiner Marítimo se apresentou mais vantajoso para construção de uma edificação residencial, no âmbito econômico e produtivo.
\end{abstract}

PALAVRAS-CHAVE: Contêiner. Concreto-PVC. Custo. Sistemas construtivos. Tempo. 


\title{
COMPARATIVE STUDY BETWEEN THE CONSTRUC TIVE SYSTEM OF MARINE CONTAINER AND CONCRETE-PVC SYSTEM IN SÃO LUIZ - MA
}

\begin{abstract}
Industrialized Construction Methods are gaining space in the Brazilian market, as more efficient and economical systems are needed in the construction industry, with a decrease in material waste and high productivity. In this research, the Constructive Method with Maritime Container, which uses the container itself to construct buildings, and the Concrete-PVC Method, which uses PVC profiles, are embedded with each other and filled with concrete and steel, forming the walls of the edification. With this, a comparative study was made between these methods and identified the most feasible one for the construction of a housing in the city of. For this, a bibliographical research was carried out and the architectural, structural and complementary projects of a standard residence were elaborated, as well as the budget worksheets, the equipment sizing and the execution planning of the work, for each method. The results showed that the method with Maritime Container presents savings of $R \$ 1,352.44$ in total cost and lower cost of labor, with a difference of $R \$$ 1,167.60. This system also had an advantage in execution time, requiring only 19 days, while Concrete-PVC needs 27 days. Thus, the construction system with Maritime Container was more advantageous for the construction of a residential building, in the economic and productive scope.
\end{abstract}

KEYWORDS: Constructive Systems. Container. Concrete-PVC. Cost. Time.

\section{INTRODUÇÃO}

Devido à expansão dos centros urbanos no final do século XIX, a demanda por habitações aumentou, resultando em uma fragmentação em subsetores da atividade construtiva. Utilizando o método tradicional como principal sistema construtivo, a construção civil passou a apresentar baixa produtividade, além de possuir alto índice de desperdício de material, fazendo as construtoras procurarem por alternativas construtivas baseadas na racionalização (SALGADO, 1996).

Assim, este processo de industrialização da construção civil é caracterizado pela redução dos desperdícios e volume de resíduos nas obras, além de possuir uma diminuição do número de recursos humanos usados como mão de obra, uma vez que são inseridas estruturas pré-fabricadas e utilizados equipamentos mecânicos, apresentando ganho de produtividade e qualidade. A racionalização inicia-se, desta forma, com a definição do projeto, com suas informações e especificações. Logo após, o tipo de projeto é definido para que haja uma produção em série. A última etapa corresponde à montagem das peças, dando origem à edificação (FACCO, 2014).

A construção civil é responsável por grande parte do impacto ambiental, devido ao consumo excessivo de recursos naturais, alta demanda por matéria prima industrializada e a geração de resíduos (DILIGENTI, 2010). Com isso, a fim de obter uma construção sustentável, o emprego de sistemas construtivos ecologicamente corretos, que economizem ao máximo os recursos naturais e preserve o meio ambiente, vem ganhando bastante interesse das construtoras e dos clientes.

Os autores buscaram identificar dentre os métodos construtivos com contêiner marítimo e concreto-PVC o mais viável para construção de uma edificação residencial na cidade de São Luís, Maranhão. 


\section{FUNDAMENTAÇÃO TEÓRICA}

Para garantir maior durabilidade, o contêiner deve passar por um tratamento para curar existentes ou futuras oxidações, ferrugem, corrosão, etc. Após realizar a limpeza, deve-se pintar o contêiner, dentro e fora, com um material anticorrosivo, sendo que a pintura interna não necessita de um acabamento perfeito, tendo em visto que receberá revestimento. A pintura externa pode ser de esmalte sintético, tinta automotiva ou tinta à base de poliuretano (OLIVEIRA, 2016).

Quanto ao revestimento, há uma variedade de materiais que podem ser usados, como gesso acartonado, placas de compensado, placas OSB, placas cimentícias e chapas de MDF. E para o acabamento final, existe a possibilidade de revestimento argamassado com cerâmica ou porcelanato, papel de parede, dentre outros. Além de que, em relação ao piso, o próprio contêiner já possui um piso original, que consiste em um material de compensado naval, que pode ser mantido ou adicionado outros revestimentos (SOUZA et al., 2019).

O método construtivo utilizando contêiner marítimo apresenta vantagens como rapidez na execução, obra mais limpa, reciclagem e pouca geração de resíduos, além de que construções duradouras e sustentáveis. Entretanto, a principal desvantagem deste método construtivo corresponde ao baixo pé direito da estrutura, o que dificulta a circulação do ar. Além disso, devido a possibilidade de contaminação com relação à carga transportada, para reutilização dos contêineres para construção de edifício, é necessário um licenciamento ambiental, além de realizar uma desinfecção e teste de radioatividade. É necessária mão-de-obra especializada para efetuar os recortes na estrutura do contêiner, movimentação e montagem dos módulos, além de ter alto custo com transporte.

\section{Sistema Construtivo de Concreto-PVC}

O Sistema Construtivo de Concreto-PVC, internacionalmente conhecido por Royal Building, foi criado na década de 80, no Canadá, pelo Royal Group Technologies. Entretanto, esta inovação chegou no território brasileiro apenas em 1998 com a execução de uma escola em Macaé, no Rio de Janeiro. Caracterizado por sua facilidade e rapidez de execução, com caráter inovador, passou a ganhar mercado e, hoje, se tem mais de $500.000 \mathrm{~m}^{2}$ de área construída, nos mais variados tipos de construções, desde pequenos projetos, indústrias, lojas, escolas, residências de alto padrão, até edifício de quatro pavimentos (IBDA, 2018).

O método consiste na associação de perfis de PVC vazados, que encaixam entre si, formando as paredes da edificação. São preenchidos internamente com concreto e aço estrutural e permite construir desde edificações térreas ou geminadas, até sobrados (CICHINELLI, 2013). A diferença em relação ao sistema convencional de formas está no fato de que as peças de PVC incorporam a construção, servindo para edificação como seu acabamento final, não necessitando, desta forma, de um revestimento, sendo pintura ou algum tratamento.

A escolha do tipo de fundação não depende do método de construção a ser utilizado, e sim do tipo de solo e sua resistência, obtida através do estudo de sondagem. Como, geralmente, as construções são de pequeno porte, executa-se as fundações rasas, como radier, vigas baldrames ou sapatas corridas (CICHINELLI, 2013).

Para iniciar o processo construtivo, é necessário demarcar a posição das paredes no radier. A marcação das paredes é feita baseada em um ponto de referência, que deverá ser um dos cantos da edificação. É necessário, após 
demarcação, colocar as ancoragens das paredes, sendo possível colocar antes de concretar a fundação ou depois. As barras são colocadas ao longo das paredes, em cada intersecção e ao lado de cada porta e janela. $O$ diâmetro deverá ser de $10 \mathrm{~mm}$ e altura de $1000 \mathrm{~mm}$, e deverá ser distanciada entre si, no máximo, de $600 \mathrm{~mm}$ (BAZZE, 2018).

Após realizado o posicionamento da ancoragem e gabarito das paredes, pode-se iniciar a montagem dos módulos de PVC. A montagem das paredes, com as peças encaixadas longitudinalmente, deve iniciar pelos cantos da edificação, montando dois trechos da parede formando um "L". Deve iniciar o processo pelas paredes perimetrais e posteriormente executar a montagem das paredes internas. Há alguns locais das paredes que necessitam ser adicionadas barras de aço, em conjunto com a montagem das paredes, que servirão de reforço estrutural. Os reforços horizontais são colocados sobre as paredes e nas vergas e contravergas de portas e janelas. Já os reforços verticais, são posicionados no encontro de paredes e ao lado de cada vão de porta e janela (BAZZE, 2018).

É necessário realizar o escoramento dos perfis de PVC para estabilizar o conjunto e mantê-los em prumo e esquadro. Deve iniciar a medida em que as paredes vão sendo montadas, sendo que a distância entre estas não pode ser superior a três metros, e só finalizar quando todas as instalações hidrossanitárias e elétricas são instaladas, pois durante este processo pode ser necessário inserir mais algum painel (BAZZE, 2018).

A última etapa, antes de iniciar a concretagem das paredes, corresponde às instalações hidrossanitárias e elétricas. Em relação à instalação hidráulica, podem ser utilizados tubos convencionais e deve ser priorizado o circuito vertical, sendo que as conexões devem ser utilizadas na base ou topo das paredes. Quanto às instalações de esgoto, estas devem passar por fora da parede, para que não comprometer a estrutura da parede, devido às espessuras destas tubulações. Para as instalações elétricas, os eletrodutos podem ser rígidos ou corrugados e, igualmente às instalações hidrossanitárias, não podendo ser na horizontal, sendo que cada ponto elétrico terá um condutor elétrico que sobe ou desce (ROYAL, 2018).

Para preencher os perfis de PVC, deve ser utilizado o concreto auto adensável, com resistência mínima de $20 \mathrm{MPa}$ (CICHINELLI, 2013). Conforme Schmidt (2013), a concretagem inicia pelos peitoris e contravergas das janelas, sendo que o lançamento do concreto não deve iniciar apenas em um ponto, e sim distribuindo-o por toda extensão da parede. Após, coloca-se os pré-marcos e escora. Em seguida, segundo Royal (2018), a concretagem é prosseguida por todas as paredes em camadas de $60 \mathrm{~cm}$, em um tempo máximo de 45 minutos, seguindo um circuito. Sendo que, após completar a primeira camada de $60 \mathrm{~cm}$, deve-se retornar ao ponto inicial para começar a outra camada, até completar toda a parede.

As instalações das janelas e portas inicia-se após finalizada a execução das paredes e lajes e, como os perfis de PVC servem como acabamento da edificação, a utilização de outro tipo de revestimento, como cerâmica ou pintura, torna-se opcional (SCHMIDT, 2013).

Da mesma forma que outros sistemas construtivos, o método ConcretoPVC apresenta resultados tanto satisfatório como insatisfatório. As paredes de PVC não necessitam de manutenção frequente, sendo necessário apenas uma limpeza com água e sabão, obtendo, assim, quase custo zero de manutenção. Conforme Santos (2015), os perfis de PVC são leves, facilitando o transporte e montagem, 
mesmo em locais de difícil acesso, sem necessidade de guindastes ou ferramentas pesadas, além de que não necessitam de revestimento, pinturas ou tratamentos, sendo que estas aceitam receber qualquer tipo de acabamento, caso desejado. $O$ método construtivo em questão possui alta velocidade de execução e utiliza pouco material e mão de obra, resultando na diminuição dos custos, além de apresentar um bom desempenho em relação às intempéries e baixo impacto ambiental. Caso a arquitetura passe por mudanças, pode haver perda de material, uma vez que as peças são feitas sob medidas.

\section{MATERIAL E MÉTODOS}

A pesquisa foi dividida em cinco etapas metodológicas, seguida da análise dos resultados, que iniciou com uma pesquisa bibliográfica a respeito do assunto abordado. Após, utilizou-se uma planta padrão de uma residência e desenvolveu-se projetos arquitetônicos, estruturais e complementares, segundo cada sistema construtivo. Por fim, foi realizado o estudo de produção e de orçamento, através dos levantamentos de quantitativos, do custo direto e tempo de execução. Com todas estas etapas concluídas, foi possível analisar os dados obtidos e alcançar os resultados.

\section{Pesquisa Bibliográfica}

A primeira etapa metodológica consistiu no aprofundamento a respeito do tema em estudo, através da literatura disponível. Sendo assim, foram utilizados dissertações, livros, artigos científicos, manuais de normatização, normas técnicas, legislações, teses de monografia e pós-graduação, além de websites e outras fontes que abordaram os métodos construtivos pertinentes ao trabalho.

Buscou-se, nesta parte, entender o funcionamento e as particularidades de cada método construtivo, identificando as principais características, vantagens e desvantagens, além de identificar as limitações. Tais informações foram essenciais para tomada de escolhas nas demais etapas.

\section{Elaboração dos Projetos}

A pesquisa foi iniciada no primeiro semestre seguindo um cronograma a partir do dia 15 de fevereiro de 2018 com finalização no segundo semestre, em 20 de outubro de 2018, afim de se executar na cidade de São Luís - MA. Para o estudo comparativo, foi utilizada planta padrão de uma residência para ambos os métodos, desenvolvida e idealizada pelos autores, a qual foi projetada de forma a atender as dimensões do contêiner, uma vez que o sistema de Concreto-PVC apresenta maior flexibilidade para adaptação das dimensões, por possuir no mercado vários tipos de módulos. A figura 1 mostra a planta baixa da residência padrão utilizada nesta pesquisa. 


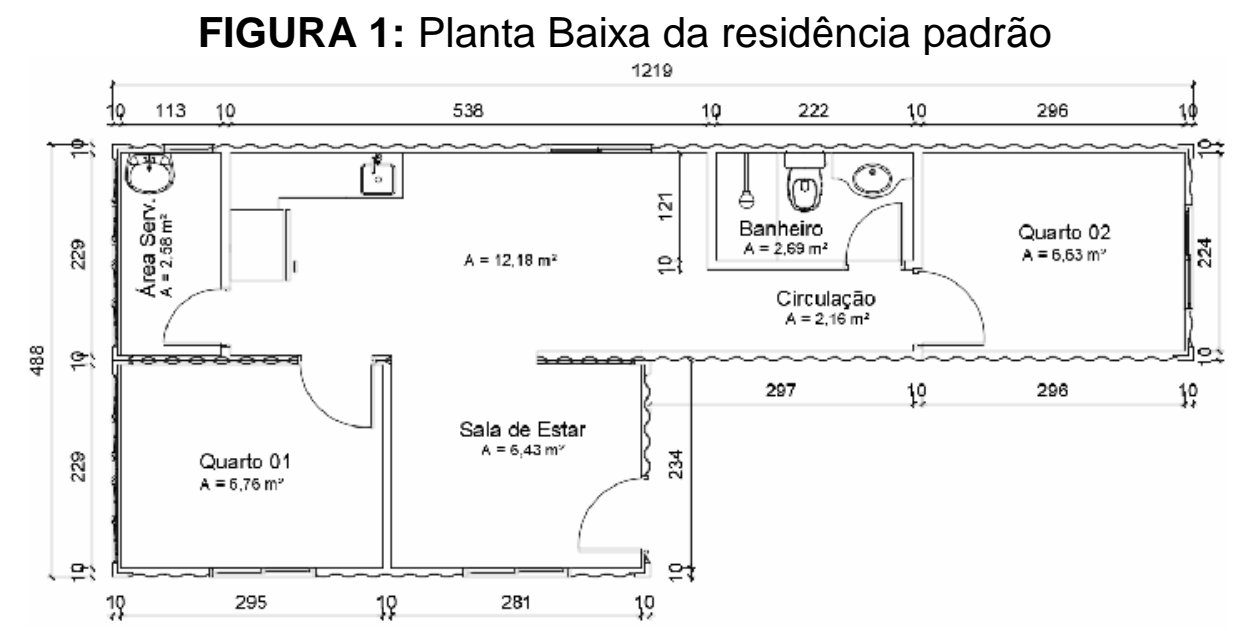

FONTE: Autores, (2018)

Para o método construtivo com contêiner marítimo, foi utilizado um contêiner Dry Box 20 pés e um contêiner Dry Box 40 pés, unindo-os pelo painel lateral, servindo como a própria estrutura da edificação. Respeitando as limitações e características do método, foram utilizadas paredes com 10 centímetros de espessura. Como a caixa metálica já possui cobertura, não utilizou fechamento superior, sendo feito apenas uma impermeabilização, e foi utilizado o piso original do contêiner, que consiste em compensado naval de madeira. Além disso, para proporcionar conforto ao usuário, foi colocada lã de rocha como isolamento térmico e acústico. As paredes externas foram revestidas com pintura e as paredes internas foram executas em drywall.

Por se tratar de uma estrutura autoportante, o contêiner consegue distribuir uniformemente as tensões no solo, sendo, dessa forma utilizado pequenos blocos de concreto em suas extremidades como fundação. E conforme a literatura, optou-se por colocar um SPDA (Sistema de proteção contra descargas atmosféricas) para melhor segurança. Quanto às instalações elétricas e hidrossanitárias, estas foram projetadas igualmente ao método tradicional.

Quanto ao outro método, por se tratar de uma residência de baixo padrão, optou-se por utilizar módulos de PVC de oito centímetros de espessura, que correspondem à própria parede da edificação, dispensando a utilização de isolamento termoacústico, instalação SPDA e de revestimento. Estas foram preenchidas com concreto auto-adensável e reforço com aço estrutural, nos devidos locais previstos no projeto. Houve a necessidade de aumentar um centímetro no comprimento total da residência, para compatibilização das dimensões. A cobertura foi feita de estrutura de madeira com telha cerâmica do tipo colonial e utilização de piso cerâmico, além disso, foram usadas sapatas corridas como infraestrutura, considerando 0 porte da edificação. Quanto às instalações elétricas e hidrossanitárias, projetou-se levando em consideração as limitações do método, no qual não é permitido tubulações horizontais, com exceção de trechos não estruturais de até um terço do comprimento da parede, não ultrapassando um metro.

\section{Levantamento do Quantitativo dos Materiais}

Obtidas todas as informações pertinentes para cada sistema, foi possível identificar quais serviços, materiais e mão de obra seriam necessários para execução da obra. Para orçar esta execução, realizou-se o levantamento do quantitativo de cada material e serviço, com base nas informações obtidas. 
Como o enfoque da pesquisa consistiu em um estudo comparativo entre os métodos, foi levado em consideração apenas as etapas construtivas que se diferenciam entre os dois métodos construtivos, sendo alguns itens, dessa forma, dispensados por serem iguais entre os métodos ou possuírem pouca representatividade para o objetivo da pesquisa.

\section{Levantamento do Custo Direto}

Para realizar o levantamento do custo direto, utilizou-se o Sistema Nacional de Pesquisa de Custos e Índices da Construção Civil (SINAPI - MA) como fonte para obtenção da composição de cada serviço, bem como o custo unitário e mão de obra necessária, auxiliando na elaboração do orçamento. Assim, estas tabelas possuem seus respectivos insumos, coeficientes de consumo e custo unitário. A base consistiu na tabela de regime não desonerado, fornecida pela Caixa Econômica Federal, no Maranhão, e não foi considerada a taxa referente aos Benefícios e Despesas Indiretas (BDI), uma vez que isso não iria interferir no resultado final.

O SINAPI apresenta um banco de dados, o qual abrange a maioria dos serviços necessários para execução de uma edificação. Entretanto, como estes sistemas consistem em alternativos e, relativamente, recentes, houve alguns serviços que não foram encontrados nestas tabelas. Para estes, foram desenvolvidas composições próprias baseadas em outros bancos de dados, como a Tabela de Composições de Preços para Orçamentos (TCPO), além de pesquisas no mercado. Para maior fidelidade à realidade, optou-se por efetuar busca de custo e produtividade de, no mínimo, três empresas para cada caso deste, e utilizar a média dos dados disponibilizados.

Com a obtenção do custo unitário de cada serviço, material e mão de obra, assim como o índice de produtividade e com o quantitativo levantado, foi elaborada uma planilha orçamentária para cada método estudado, na qual foi obtido o custo de cada serviço e, ao somá-los, identificou-se o custo total da construção.

\section{Levantamento do Tempo de Execução}

Após realizar o levantamento do quantitativo e elaborar a planilha orçamentária, para cada método construtivo, foi possível identificar qual mão de obra seria necessária na construção, uma vez que nas composições dos serviços se tem cada profissional utilizado e seu coeficiente de produtividade.

Para aproveitamento dos profissionais, para melhor economia, foi feito um dimensionamento de equipes. Adotou-se uma jornada de trabalho de oito horas diárias e, assim, foi dimensionada uma equipe básica para cada serviço. Com a equipe básica definida, calculou-se o índice de produtividade da equipe e, utilizando os dados do quantitativo dos materiais multiplicados pelo coeficiente de produtividade, foi possível identificar quanto tempo gastaria para finalizar o serviço.

Após, realizou-se um planejamento de execução da obra, para que os profissionais fossem alocados para seus serviços de forma mais eficiente. Assim, verificou-se qual a ordem e quais serviços aconteceriam simultaneamente, para que se tivesse o mínimo possível de trabalhadores com tempo ocioso. Com isso, obtevese o tempo total de execução da obra, para cada método, de forma a representar mais fielmente a realidade.

\section{RESULTADOS}

O sistema construtivo com Contêiner Marítimo apresenta caráter sustentável a medida em que reaproveita estas embalagens que, após 10 anos de uso, são 
descartadas. Soma-se, ainda, conforme o Instituto de Pesquisa Econômica Aplicada - IPEA, (2012), o fato de que este sistema possui uma economia de, aproximadamente, $92 \%$ da geração de resíduos, já que não utilizam materiais como argamassa, concreto, blocos e outros.

Ao realizar todas as etapas metodológicas, foram obtidos dados como: custo de materiais e recursos humanos necessários para executar os serviços propostos, além do tempo total de execução da edificação, para cada método construtivo estudado. Com isso, foi possível fazer a comparação de custo direto, englobando materiais e mão de obra, e de tempo de execução entre estes. Foi possível identificar a maneira mais viável para a construção de uma residência de baixo padrão na cidade de São Luís, no Maranhão.

\section{Comparação de Custo Direto}

Para isso, desenvolveu-se uma planilha orçamentária na qual foram listados todos os serviços necessários para execução das edificações. As composições foram obtidas através do uso das tabelas do SINAPI, como referência, do mês de setembro, do ano 2018, com valores referentes ao estado do Maranhão. Entretanto, alguns itens não foram encontrados em bancos de dados, sendo utilizado, para estes casos, outras fontes como TCPO ou mesmo pesquisas de mercado, sendo consultado em, no mínimo, três empresas e utilizada a média dos valores encontrados.

Vale ressaltar que o estudo visou a comparação entre os métodos, sendo levado em consideração, dessa forma, apenas os itens que diferenciavam entre estes ou possuíam quantitativos diferentes, originando em custo diferente, uma vez que, para àqueles que eram iguais, teria um custo igual para ambos, não interferindo no resultado final.

Ao analisar os itens necessários, percebeu-se que para o método com contêiner marítimo haveria custo com serviços preliminares, correspondendo à aquisição do contêiner e sua adaptação e proteção, e com instalação de SPDA e pintura, dispensados do outro método. Em contrapartida, o sistema de ConcretoPVC necessita que seja realizada a colocação de piso, serviço dispensado no sistema de contêiner. O quadro 1 mostra o custo total de cada serviço levantado, incluindo materiais e mão de obra, obtendo o valor em cada etapa construtiva.

QUADRO 1: Comparativo de Custo entre os dois métodos por etapa construtiva

\begin{tabular}{|c|r|r|}
\hline Serviços & $\begin{array}{c}\text { Método Contêiner } \\
\text { Marítimo }(\mathrm{R} \$)\end{array}$ & Método Concreto-PVC (R\$) \\
\hline Serviços preliminares & $28.038,40$ & 0,00 \\
\hline Infraestrutura & $1.196,38$ & $7.087,36$ \\
\hline Paredes e Painéis & $9.693,71$ & $34.524,87$ \\
\hline Cobertura & $2.996,15$ & $4.291,68$ \\
\hline Instalações Hidráulicas & 650,31 & 939,28 \\
\hline Instalações SPDA & 976,66 & 0,00 \\
\hline Pintura & $4.321,83$ & 0,00 \\
\hline Forro & $1.839,02$ & $1.890,32$ \\
\hline Piso & 0,00 & $2.331,39$ \\
\hline TOTAL & $\mathbf{4 9 . 7 1 2 , 4 6}$ & $\mathbf{5 1 . 0 6 4 , 9 0}$ \\
\hline
\end{tabular}

FONTE: (Autores, 2018). 
Verificou-se que a diferença de custo global correspondeu à uma pequena porcentagem, equivalente à $2,72 \%$, que consistiu em $R \$ 1.352,44$, entre os dois métodos para valores do ano de 2018. Entretanto, analisando a diferença em relação à cada item, as etapas construtivas apresentaram uma divergência de custo significativa, com exceção da colocação de forro. As etapas com maior variação em relação às despesas correspondem exatamente àquelas que caracterizam os métodos. Os serviços preliminares, por serem essenciais para a adequação do método de Contêiner Marítimo e as paredes e painéis, fundamentais ao método Concreto-PVC.

Ao comparar os custos das etapas análogas, verificou-se que o método de Concreto-PVC apresentava custo mais elevado em todas, sendo que os itens paredes e painéis e infraestrutura correspondem aos que possuem uma variação mais significativa, em relação ao outro método. Analisando o custo estratificado de materiais e da mão de obra utilizada para realizar cada etapa construtiva, obteve-se os custos mostrados no quadro 2.

QUADRO 2: Custo de Materiais e Mão de obra, para cada método

\begin{tabular}{|c|r|r|r|r|}
\hline \multirow{2}{*}{ Serviços } & \multicolumn{2}{|c|}{$\begin{array}{c}\text { Método Contêiner } \\
\text { Marítimo }(\mathrm{R} \$)\end{array}$} & \multicolumn{2}{c|}{ Método Concreto-PVC $(\mathrm{R} \$)$} \\
\cline { 2 - 5 } & Materiais & $\begin{array}{c}\text { Mão de } \\
\text { Obra }\end{array}$ & Materiais & Mão de Obra \\
\hline Serviços preliminares & $25.861,32$ & $2.177,08$ & 0,00 & 0,00 \\
\hline Infraestrutura & 813,11 & 383,27 & $5.011,95$ & $2.075,41$ \\
\hline Paredes e Painéis & $8.709,61$ & 984,11 & $30.645,73$ & $3.879,14$ \\
\hline Cobertura & $2.233,00$ & 763,16 & $3.042,14$ & $1.249,54$ \\
\hline Instalações Hidráulicas & 360,38 & 289,93 & 566,77 & 372,50 \\
\hline Instalações SPDA & 768,42 & 208,24 & 0,00 & 0,00 \\
\hline Pintura & $2.142,29$ & $2.179,54$ & 0,00 & 0,00 \\
\hline Forro & $1.434,07$ & 404,95 & $1.474,08$ & 416,24 \\
\hline Piso & 0,00 & 0,00 & $1.766,34$ & 565,05 \\
\hline TOTAL & $\mathbf{4 2 . 3 2 2 , 2 0}$ & $\mathbf{7 . 3 9 0 , 2 8}$ & $\mathbf{4 2 . 5 0 7 , 0 1}$ & $\mathbf{8 . 5 5 7 , 8 8}$ \\
\hline
\end{tabular}

FONTE: (Autores, 2018).

Verificou-se, portanto, que houve um custo com material bem mais elevado, se comparado ao de mão de obra, e constatou-se que o método de Concreto-PCV possui um custo superior, tanto para os materiais quanto para mão de obra. Ao fazer a comparação, percebeu-se pequena diferença de custo de material entre os métodos, correspondente à, apenas, $\mathrm{R} \$ 184,81$, entretanto a mão de obra apresentou custo de $\mathrm{R} \$ 1.167,60$ superior.

Analisando os dados de forma global, calculou-se o valor por metro quadrado, para que a comparação pudesse representar mais fielmente a realidade. Teve-se que o método com contêiner marítimo gerou um custo menor, correspondendo a $\mathrm{R} \$$ $1.116,40$ por metro quadrado, enquanto o método de concreto-PVC apresentou custo de $R \$ 1.146,50$ por metro quadrado.

\section{Comparação de Tempo de Execução}

Ao realizar o dimensionamento de equipes básicas, foi determinada a quantidade de profissionais, tanto oficiais quanto auxiliares, necessários para 
execução de cada serviço. O planejamento de execução foi feito de forma a aproveitar a mão de obra para que todos ficassem com menor tempo possível de ociosidade. Assim, para o sistema construtivo com Contêiner Marítimo, obteve-se, através do dimensionamento, a equipe de trabalhadores composta por dois serventes, quatro pedreiros, quatro armadores, um encanador, quatro montadores, três carpinteiros, um eletricista, três pintores, um serralheiro, um soldador e cinco impermeabilizadores para executar os serviços analisados neste estudo, presentes na planilha orçamentária referente a este método.

Em contrapartida, verificou-se que, para o sistema construtivo Concreto-PVC, a equipe de trabalhadores, para execução dos serviços levantados, foi formada por três serventes, quatro pedreiros, quatro armadores, um encanador, um montador, três carpinteiros, um telhadista e dois ladrilhistas. Percebeu-se, portanto, que alguns profissionais utilizados no outro método também foram usados neste sistema, entretanto, este método necessitou de uma equipe menor, ou seja, menos trabalhadores.

Ao utilizar o índice de produtividade da equipe básica de cada serviço e ao efetuar o planejamento de execução da obra, considerando uma jornada de trabalho de oito horas diárias, obteve-se o tempo de execução de cada etapa construtiva. Os quadros 3 e 4 apresentam um resumo da quantidade de dias previstos para realizar cada etapa, após planejamento, para o método com Contêiner Marítimo e ConcretoPVC, respectivamente.

QUADRO 3: Tempo de execução, por item, para o Método com Contêiner Marítimo

\begin{tabular}{|c|r|}
\hline Serviços & \multicolumn{2}{|c|}{ Método Contêiner Marítimo } \\
\hline Itens & Dias \\
\hline Serviços preliminares & 13,25 \\
\hline Infraestrutura & 5,5 \\
\hline Paredes e Painéis & 1,92 \\
\hline Cobertura & 1,0 \\
\hline Instalações Hidráulicas & 1,42 \\
\hline Instalações SPDA & 6,27 \\
\hline Pintura & 8,6 \\
\hline Forro & 2,33 \\
\hline
\end{tabular}

FONTE: (Autores, 2018)

QUADRO 4: Tempo de execução, por item, para o Método Concreto-PVC

\begin{tabular}{|c|r|}
\hline Serviços & \multicolumn{1}{|c|}{ Método Concreto-PVC } \\
\hline Itens & Dias \\
\hline Infraestrutura & 23,8 \\
\hline Paredes e Painéis & 10,23 \\
\hline Cobertura & 1,8 \\
\hline Instalações Hidráulicas & 2,31 \\
\hline Forro & 4,32 \\
\hline Piso & 2,39 \\
\hline
\end{tabular}

FONTE: (Autores, 2018)

Constatou-se que utilizando a equipe básica, para o método com Contêiner Marítimo, necessitaria de 19 dias para finalizar as etapas construtivas, enquanto o ENCICLOPÉDIA BIOSFERA, Centro Científico Conhecer - Jandaia-GO, v.17 n.33; p. 441 2020 
método Concreto-PVC precisaria de 27 dias para executar todos os serviços previstos, adotando a mesma jornada de trabalho diária. Com isso, fez-se um outro planejamento de execução, porém, agora, para aquele em que demandaria maior tempo, que consistiu no Concreto-PVC, neste caso, determinando que a obra fosse executada no mesmo tempo que o sistema com Contêiner Marítimo, a fim de averiguar o acréscimo de mão de obra que seria necessário. Ao analisar, percebeuse que, para que a edificação ficasse pronta em 19 dias, seria necessário utilizar duas equipes na escavação manual da vala da infraestrutura e três equipes na construção das paredes com os módulos de PVC. Esta mudança acarretaria um acréscimo no custo da mão de obra, uma vez que teria que contratar mais nove serventes e dois pedreiros. $O$ quadro 5 apresenta o custo para contratação destes profissionais.

QUADRO 5: Custo acrescido da mão de obra para método Concreto-PVC

\begin{tabular}{|c|c|c|c|c|c|c|c|r|}
\hline Serviço & $\begin{array}{c}\text { Mão de } \\
\text { Obra }\end{array}$ & Unidade & Quant. & Preço/H & $\begin{array}{c}\text { Jornada de } \\
\text { Trabalho } \\
(H)\end{array}$ & $\begin{array}{c}\text { Preço por } \\
\text { dia }(\mathrm{R} \$)\end{array}$ & $\begin{array}{c}\text { Dias } \\
\text { trabalhad } \\
\text { os }\end{array}$ & $\begin{array}{c}\text { Preço } \\
\text { Total }(\mathrm{R} \$)\end{array}$ \\
\hline $\begin{array}{c}\text { Escavação da } \\
\text { Vala }\end{array}$ & Servente & Unid. & 1 & 10,14 & 8 & 81,12 & 2 & 162,24 \\
\hline $\begin{array}{c}\text { Paredes de } \\
\text { PVC }\end{array}$ & Servente & Unid. & 8 & 10,14 & 8 & 81,12 & 3 & $1.946,88$ \\
\cline { 2 - 9 }$y$ & Pedreiro & Unid. & 2 & 14,40 & 8 & 115,2 & 3 & 691,2 \\
\hline
\end{tabular}

FONTE: (Autores, 2018).

Sendo assim, o orçamento total para a construção da edificação passaria a custar equivalente a $\mathrm{R} \$ 53.865,30$, esta diferença corresponderia a $8,35 \%$, o valor de $\mathrm{R} \$ 4.152,84$ a mais que o método com Contêiner Marítimo.

\section{DISCUSSÃO}

A partir do momento em que a sociedade exigiu práticas e ações que visassem redução dos impactos ambientais, surgiram os sistemas construtivos sustentáveis, que utilizam materiais ecologicamente corretos, esta iniciativa gera economia no uso de recursos naturais e redução na emissão de gases de efeito estufa, entre este o sistema construtivo com contêiner marítimo (FERREIRA et al., 2010).

\section{Sistema Construtivo com Contêiner Marítimo}

$\mathrm{Na}$ última década, os contêineres passaram a ganhar popularidade na área da construção civil, não mais restringido a barracos, como foram utilizados por muito tempo, mas sim como sistema construtivo para os mais variados tipos de edifícios, como prédios residenciais, comerciais, dentre outros. Apesar de sua popularidade nesta área, o uso dos contêineres para construções no Brasil é recente, conforme Portal Metálica (2015), sendo que a primeira edificação construída foi uma loja para empresa Container Ecology Store, em 2010. A primeira residência, utilizando este método construtivo, foi feita em 2011, em São Paulo, pelo arquiteto Danilo Corbas, com alto nível de complexidade, conforme mostra a figura 2. 
FIGURA 2: Residência em contêiner do arquiteto Danilo Corbas

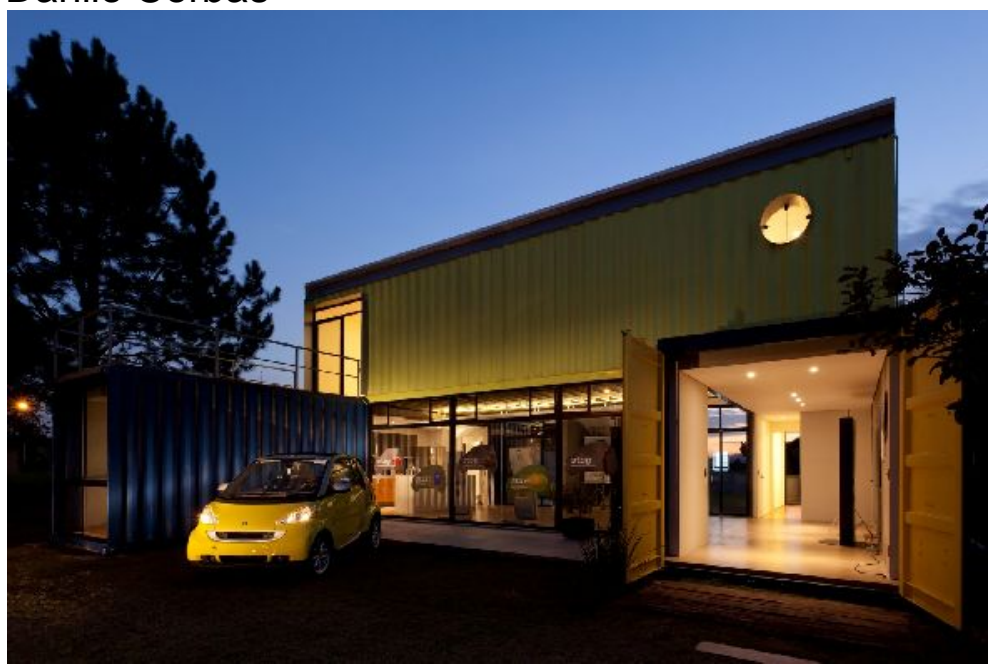

FONTE: SUSTENTARQUI (2014)

De acordo com Kotnik (2013), este método ganhou gosto pelos arquitetos e engenheiros, devido a facilidade e rapidez de execução, apresentando menor custo, por serem pré-fabricados, além de que possui caráter sustentável, com reutilização e reciclagem de materiais. Conforme Keeler e Burke (2010), para que estes recipientes possam ser utilizados na construção civil, é necessário que sejam submetidos ao tratamento antiferrugem e pintura impermeabilizante, e ainda, que passem por uma reforma, caso seja uma peça reutilizada, na qual são adaptadas com aberturas de janelas e portas, seguindo o projeto arquitetônico, e suas superfícies são regularizadas.

Os contêineres constituem em um recipiente feito em aço, alumínio ou fibra, geralmente em grandes dimensões, destinados ao acondicionamento e transporte de cargas, em transporte marítimo, terrestre e aéreo, para longas distâncias. Segundo Milaneze et al., (2012), sua vida útil corresponde, em média, 10 anos, após esse período a manutenção se torna economicamente impraticável e são descartados nas cidades portuárias sendo necessário encontrar um destino correto para estas peças, por serem feitos de materiais metálicos e não biodegradáveis. Dentre os modelos de contêineres marítimos disponíveis na indústria, os mais utilizados para construção civil são: Dry Standard, High Cube e Open Side, sendo este último utilizado em menor escala.

Ao se optar por executar uma obra usando o método construtivo em contêiner, a primeira etapa de execução consiste na escolha do contêiner. Segundo Castilho e Ikegami (2015), é obrigatório que o contêiner seja nacionalizado para ser possível fazer alterações em sua estrutura, pois isso ocasionará alterações de características originais. Após isso, deverá ter cuidado a respeito dos riscos radioativos e biológicos. É feita uma análise do contêiner e emitido laudos de descontaminação, entregues no ato da compra, garantindo que estes contêineres não apresentarão risco a saúde.

No processo da construção utilizando contêiner, um ponto crítico consiste na adaptação ao projeto. Muitos cortes enfraquecem a estrutura do contêiner, tornando necessário realizar reforços estruturais. Além disso, devido ao contêiner ser autoportante, este é sustentado por quatro extremidades, e quando ocorrem muitos 
cortes, deve-se implementar mais pontos de apoio, aumentando o número de fundações (MINHA CASA CONTAINER, 2016). Por se tratar de uma estrutura autoportante, o contêiner consegue distribuir uniformemente as tensões no solo, sendo utilizadas fundações do tipo rasa para este tipo de construção.

Os sistemas elétricos e hidrossanitário são executados da mesma forma que obras convencionais e, devido ao caráter metálico, por questões de segurança, deverá possuir um Sistema de Proteção contra Descargas Atmosféricas (SPDA) atendendo às normas NBR 5419 e NBR 5410. Além de que, nesse tipo de construção, para torná-lo habitável, deve-se ter cuidado em deixar aberturas que permitam ventilação cruzada, além de utilizar isolamento termoacústico para garantir conforto aos usuários, uma vez que essa caixa metálica se caracteriza por ser um ótimo condutor de calor e péssimo isolante acústico.

Os módulos de PVC são formados por duplo encaixe do tipo macho-fêmea. Caracterizam-se por serem leves e de fácil manuseio, contribuindo para praticidade de transporte e montagem, sendo entregues pelos fornecedores devidamente identificados e recortados, segundo medidas previstas pelo projetista. As peças possuem aberturas internas cuja finalidade é permitir a passagem do concreto e criar uma estrutura monolítica. Existem vários tipos de peças, sendo que cada uma possui uma função e posição exata na modulação das paredes (ROYAL, 2018). A figura 3 mostra o esquema representativo da parede de uma edificação construída com este sistema.

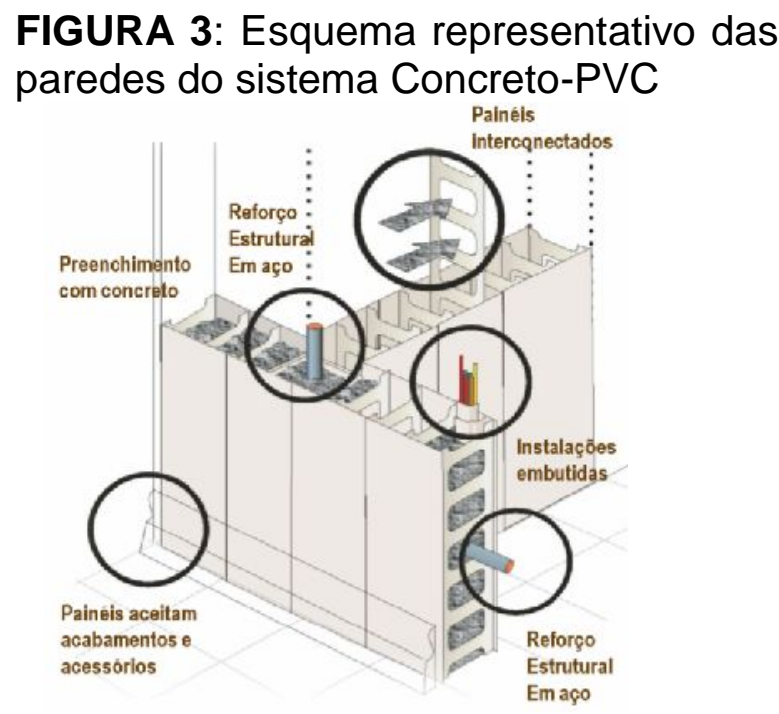

FONTE: ADEMAR; CAMARGOS (2017)

Em relação ao Sistema Construtivo Concreto-PVC, esta metodologia ainda não foi difundida no Maranhão, entretanto já se encontra em várias regiões do País como alguns autores destacaram anteriormente. A tecnologia consiste no encaixe de módulos vazados de PVC, preenchidos por concreto auto-adensável e barras de aço para reforço estrutural, formando a própria parede da edificação, dispensando acabamento. Assim como o outro método, apresenta vantagens como alta produtividade e baixa geração de resíduos, além de menor consumo de recursos naturais. Porém, ainda não se tem a possibilidade de arranjos arquitetônicos mais ousados e, devido aos módulos serem feitos sob medida, mudanças na arquitetura pode levar à perda de material. 


\section{CONCLUSÃO}

A construção civil representa papel fundamental para o País, no âmbito econômico e social. Além da grande capacidade de geração de emprego e riquezas, este setor é capaz de reduzir o elevado índice de déficit habitacional apresentado pelo País. A crescente demanda por habitações leva a necessidade por métodos construtivos industrializados e inovadores, capazes de aumentar a produtividade, de forma econômica e sustentável, mantendo a qualidade da edificação e proporcionando conforto aos moradores.

Percebeu-se, por conseguinte, com esta pesquisa, que o sistema construtivo com Contêiner Marítimo se mostrou mais vantajoso e mais viável, em comparação ao sistema Concreto-PVC, para construção de uma residência na cidade de São Luís, no Maranhão, por apresentar economia financeira e de produtividade, além de consistir em um método seguro, sustentável e de fácil execução, validando assim o objetivo da pesquisa.

\section{REFERÊNCIAS}

BAZZE PVC. Manual de Montagem: Construções Residências com Paredes Estruturais de Perfis de PVC Preenchidos com Concreto. Portão, Rio Grande do Sul, 2018.

CASTILHO, P; IKEGAMI, T. F.; Como escolher um contêiner para sua casa. Blog Minha Casa Container. 2015. Disponível em: <http://minhacasacontainer.com/2015/04/30/ como-escolher-um-container-para-suacasa/>. Acesso em: 10 de agosto de 2018.

CICHINELLI, G. Sistemas construtivos para casas e sobrados usa painéis de PVC preenchidos com concreto. Revista Téchne, Edição 199. 2013. Disponível em < http://techne17.pini.com.br/engenharia-civil/199/artigo299968-1.aspx>Acesso em 01 de setembro de 2018.

DILIGENTI, M.; ALBANO, F.; CANOVA, C.; FRANCISCATTO, B.; SIMON, M. Habitação Unifamiliar Sustentável: Projeto de Casa Laboratório. In.: Congresso Internacional de sustentabilidade e habitação de interesse social. Artigos. Porto Alegre, p. 3251-3254.2010.

FACCO, I.R.; Sistemas Construtivos Industrializados para Uso em Habitações de Interesse Social. 2014. 85f. Monografia (Graduação em Engenharia Civil) Universidade Federal de Santa Maria, Santa Maria - Rio Grande do Sul, 2014.

FERREIRA, M. A.; CARVALHO, R.C.; ELLIOTT, K.S.; Avanços para análise e projeto em estruturas pré-moldadas com ligações semi-rígidas. Concreto e Construção, v. 59, p. 70-77, 2010.

IBDA. Instituto Brasileiro de Desenvolvimento da Arquitetura. Concreto e PVC, um casamento promissor. $2018 . \quad$ Disponível em: $<$ http://www.forumdaconstrucao.com.br/conteudo.php?a=43\&Cod=1274>. Acesso em: 22 out. 2018. 
IPEA. Diagnóstico dos Resíduos Sólidos da Construção Civil - Relatório de Pesquisa, $2012 . \quad$ Disponível em: <http://www.ipea.gov.br/agencia/images/stories/PDFs/relatoriopesquisa/120911_relat orio_co nstrucao_civil.pdf>. Acesso em: 09 de setembro de 2018.

KEELER, M.; BURKE, B. Fundamentos de Projeto de edificações sustentáveis. Porto Alegre: Bookman. 2010.

KOTNIK, J. New Container Architecture. Editor: Links, Linksbooks.Net, Barcelona Spain, 2013.

MILANEZE, G. L. S.; MACHADO, L. T.; DA SILVA, R.; BITTENCOURT, L. F.; BIELSHOWSKY, B. B. A utilização de containers como alternativa de habitação social no município de Criciúma/SC. 1ำ Simpósio de Integração Científica e Tecnológica do Sul Catarinense, IFSC, Santa Catarina, 2012.

MINHA CASA CONTAINER. Sobre containers na construção civil. Disponível em: $<$ https://minhacasacontainer.com/>. Acesso: em 28 agosto de 2018.

OLIVEIRA, J. R. Manual de construção Casa Container - Passo à passo. Penha, 2016.

PORTAL METÁLICA. Container City: um novo conceito em arquitetura sustentável. 2015. Disponível em: <http://wwwo.metalica.com.br/container-city-umnovo-conceito-emarquitetura-sustentavel>. Acesso em: 24 set. 2018.

ROYAL. Tecnologia Construtiva Concreto-PVC: Construindo um Mundo Melhor. Ficha Técnica, Versão 1.0, 2018.

RODRIGUES, A.S.C.; MARQUES, C.M.N.S.; HOLANDA, E.P.T.; NASCIMENTO, F.B.C.; Otimização e desenvolvimento Brasileiro no sistema de Construção Civil: Concreto PVC. Cadernos de graduação, v.4, n. 2, p. 135-150, nov/2017

SALGADO, M. S. Metodologia para seleção de sistemas construtivos destinados à produção de habitações populares. 1996. 224f. Tese (Doutorado em Engenharia de Produção) - Universidade Federal do Rio de Janeiro, Rio de janeiro, 1996.

SANTOS, M.C.D.; Análise do sistema construtivo concreto - PVC em relação à logística de transporte para construção da Estação Científica da llha da Trindade (ECIT). 2015. 107f. Dissertação (Mestrado em Engenharia Urbana e Ambiental) - Pontifícia Universidade Católica do Rio de Janeiro, Rio de Janeiro, 2015.

SCHMIDT, V. L.; Paredes estruturais constituídas de painéis de PVC preenchidos com concreto: análise das potencialidades do sistema. Trabalho apresentado (TCC) para conclusão de curso à Universidade Federal do Rio Grande do Sul, escola de Engenharia. 2013. Disponível em 
https://www.lume.ufrgs.br/bitstream/handle/10183/79788/0008536.pdf?sequence=1, acesso em 17/09/2020.

SOUZA, D. A.; PINHO, G. C.S.; ANDRADE, R. G. M.; ARAÚJO, G. S. Sistema construtivo contêiner para Habitação Social: desafios de implantação e possibilidades construtivas. Brazilian Journal of Development, v. 5, n. 11, p. 25836-25862, 2019.

SUSTENTARQUI, Redação. 3 casas brasileiras sustentáveis. SustentArqui, 2014. Disponível em: <https://sustentarqui.com.br/3-casas-brasileiras-sustentaveis/> Acesso em: 13 de setembro de 2020. 